\title{
Sufisme Pedesaan dan Nalar Beragama Inklusif: Ekspresi Keagamaan Majelis Dzikir Birrul Walidain di Karanganyar Jawa Tengah
}

\author{
Mibtadin Mibtadin ${ }^{1 *}$, Zainal Habib ${ }^{2}$, Mustolehudin Mustolehudin ${ }^{3}$ \\ Universitas Sebelas Maret (UNS) Surakarta, Indonesia; mibtadianisahmad@staff.uns.ac.id \\ UIN Maulana Malik Ibrahim Malang, Indonesia; zainalhabib77@gmail.com \\ 3 Balai Penelitian dan Pengembangan Agama Semarang, Indonesia; mustolehuddin@gmail.com \\ * Correspondence: mibtadianisahmad@staff.uns.ac.id
}

Received: 2020-12-08; Accepted: 2021-06-02; Published: 2021-07-25

\begin{abstract}
This research focuses on how the community in Karangwuni Village Karangmojo Tasikmadu, Karanganyar Regency expresses religious movements as an effort to build a moderate society. Majelis Dzikir and Shalawat Birrul Walidain in the village are very strategic public spaces to instill an inclusive Islamic character. Village communities are synonymous with harmonious behavior and mutual help, and from a diversity perspective, they tend to be open or moderate. This study uses the sociology of religion approach with qualitative methods. This study found that makes taklim in the village became a medium for spiritual empowerment as well as a space for culture. Besides that, the Birrul Walidain taklim assembly is also a public space that displays moderate Islam in the countryside. This study offers the need for a moderate socio-religious movement carried out massively throughout the villages in the archipelago to build a tolerant Islam by prioritizing the principles of tawassuth, tawazun, and tasamuh, to create a peaceful and harmonious society. The existence of an inclusive taklim assembly can be a social capital in building a moderate society.
\end{abstract}

Keywords: Moderate Islam; Religoius Expression; Rural Community; Spirituality.

Abstrak: Studi ini memfokuskan tentang bagaimana masyarakat di Desa Karangwuni Karangmojo Tasikmadu Kabupaten Karanganyar mengekspresikan gerakan keagamaan sebagai upaya membangun masyarakat yang moderat. Tujuan penelitian ini mengulas majelis taklim Birrul Walidain menjadi media yang efektif dalam membentuk karakter dan identitas jamaah yang toleran. Majelis Dzikir dan Shalawat Birrul Walidain di desa tersebut, merupakan ruang publik yang sangat strategis untuk menanamkan karakter Islam yang inklusif. Masyarakat desa identik dengan perilaku guyub rukun dan saling tolong menolong, begitu pula dalam hal keberagamaan cenderung terbuka atau moderat. Penelitian ini menggunakan pendekatan sosiologi agama dengan metode kualitatif. Studi ini menemukan bahwa majelis taklim di desa tersebut, menjadi media pemberdayaan spiritualitas sekaligus sebagai ruang gerakan kultural. Selain itu, bahwa majelis taklim Birrul Walidain juga menjadi ruang publik yang menampilkan Islam moderat di pedesaan. Studi ini menawarkan perlunya gerakan sosial keagamaan moderat yang dilakukan secara massif ke semua desa di nusantara guna membangun Islam yang toleran, mengedepankan prinsip tawassuth, tawazun, dan tasamuh, sehingga tercipta masyarakat yang damai dan harmoni. Keberadaan majelis taklim yang inklusif dapat menjadi modal sosial dalam membangun umat yang moderat.

Kata Kunci: Ekspresi Beragama; Islam Moderat; Masyarakat Pedesaan; Spiritualitas.

\section{Pendahuluan}

Majelis taklim merupakan lembaga pendidikan agama non formal yang memiliki peran membangun pemberdayaan masyarakat baik secara sosial, politik, peningkatan pendidikan masyarakat (Jadidah, 2016), pendidikan keluarga sakinah (Hasibuan, 2020), penguatan budaya religi (Nadziroh, 2020), pengembangan dakwah (Aisyah, 2018) dan penguatan ekonomi umat Islam (Nugraha, 2018). Majelis taklim merupakan budaya keagamaan yang dapat menjadi nilai tambah 
dalam menanamkan Aswaja, mensejahterakan masyarakat dan menjaga keutuhan bangsa. Peran majelis taklim dalam menyeimbangkan amanat al-diniyyah dan al-wathoniyah berdasarkan pada khittah, fikrah, dan mabda' yang dirujuk dari ajaran Islam Aswaja an-Nahdliyah (Siraj, 2013). Peran majelis taklim dalam mendidik masyarakat sangat penting untuk menyiapkan kader atau tokoh lokal dan bangsa serta melakukan konsolidasi untuk menjaga keutuhan bangsa (Siraj, 2013). Sejauh ini, pendidikan keagamaan yang diberikan majelis taklim berupa tausiyah, dzikir, shalawat, dan tahlil dimaksudkan untuk memberikan warna keislaman tersendiri untuk warganya (Erliyana \& Huda, 2019). Selain itu, majelis taklim sekaligus sebagai gerakan moral melalui tausiyah, uswah hasanah, dan mendekatkan diri kepada Tuhan sehingga jamaah mampu menjauhi konflik sosial yang dapat mengancam persatuan bangsa. Majelis taklim dapat menjadi sarana untuk aktivitas pembinaan masyarakat dalam menginternalisasikan nilai-nilai ajaran Islam (Sarbini, 2014). Tumbuh suburnya majelis taklim di nusantara, dapat menjadi media untuk pembangunan karakter dan akhlak berlandaskan pada paham Aswaja serta memiliki wawasan kebangsaan dengan menumbuhkan rasa cinta tanah air dan menekan gerakan radikalisme (Zularham, 2019).

Majelis dzikir dan shalawat Birrul Walidain adalah salah satu contoh di antara beribu-ribu majelis taklim di Jawa Tengah. Berdasarkan database yang dihimpun oleh Balai Litbang Agama Semarang, jumlah majelis taklim di Jawa Tengah berjumlah 15.599 yang tersebar di 35 kabupaten/kota (Adriyanto, 2009). Secara umum Birrul Walidain memiliki kontribusi besar dalam pembangunan sumber daya manusia melalui pendidikan keagamaan. Kontribusi tersebut adalah proses mencerdaskan dan pembangunan karakter bangsa (nation character), khususnya dalam konteks perluasan akses dan pemerataan pendidikan keagamaan di wilayah pedesaan. Karena itu, Birrul Walidain membuka akses seluas-luasnya bagi masyarakat dengan menempatkan diri sebagai "agen pemberdayaan" pada semua aspek kehidupan, baik pendidikan, dakwah, sosial, ekonomi, politik dan budaya. Majelis Dzikir dan Shalawat Birrul Walidain adalah rumah untuk pengabdian, perubahan, serta penguatan sosialekonomi berdasarkan nilai-nilai keislaman. Dalam menjalankan fungsinya sebagai agen pemberdayaan sosial keagamaan, majelis tersebut melakukan beberapa hal. Pertama, mendorong majelis taklim lainnya sebagai lembaga pendidikan keagamaan yang tetap menjadi sentral tafaqquh $f i$ ad-din mengembangkan ilmu-ilmu keislaman serta wacana kekinian seperti ekonomi, pendidikan, politik, budaya, dan lainnya yang dapat mendorong adanya proses perubahan masyarakat (Riyadi, 2019). Kedua, di tengah tantangan zaman dan perubahan global yang ada di masyarakat, majelis tersebut merespon isu-isu yang berkembang seperti pluralisme, gender, HAM, demokrasi, toleransi (Dhestiana, 2018), dan isu kemanusiaan lainnya, bahwa Islam kompatibel dengan wacana tersebut.

Majelis Dzikir dan Shalawat Birrul Walidain merupakan majelis taklim yang selama ini aktif dalam menggerakan akar rumput sebagai sebuah kekuatan civil society (Mibtadin, 2020). Kegiatan majelis taklim ini secara umum membekali jamaah dengan nilai-nilai keislaman, kesederhanaan, keikhlasan, dan kesabaran sehingga mereka mampu menjalani kehidupan sesuai dengan tata nilai agama. Pembentukan moralitas, karakter dan kepribadian jamaah ini menjadi sumbangan yang besar bagi terwujudnya masyarakat damai, toleran dan saling menghargai di tengah pluralitas bangsa. Toleransi merupakan suatu hal yang mutlak dibutuhkan dalam kehidupan berbangsa dan bernegara ditengah keberagaman (Abdullah, 2018). Salah satu wujud toleransi beragama baik intern maupun antarumat beragama adalah adanya kerjasama dalam semua eleman masyarakat (Rustan, 2018). Dalam pengajian ini, ada beberapa nilai penting yang bisa mendorong ketenangan hidup bersama di masyarakat. Pertama, majelis tersebut dengan pengajiannya membangun kesadaran bahwa mereka hidup terikat oleh struktur sosial atau gerakan sosial (Roviana, 2014) dan sistem budaya dimana ia hadir, berinteraksi, dan membangun komunikasi dengan lingkungan sekitarnya. Kedua, adanya perbedaan praktik keagamaan umat Islam di masyarakat, merupakan representasi dan ekspresi dari sistem nilai serta cara pandang tentang sesuatu yang berbeda dan disikapi secara wajar.

Majelis taklim ini secara tidak langsung telah memberikan sumbangan dalam membangun masyarakat yang beradab berdasarkan nilai-nilai keislaman dan keindonesiaan. Dengan modal dan kesadaran kultural yang dimiliki majelis ini menguatkan moralitas masyarakat dengan menjaga prinsip al-muhafadhatul 'alā qadim as-shalih wa al-aḥdu bi jadil al-aṣlah. Majelis ini juga meringankan beban 
pemerintah dalam "ngemong (menjaga)" masyarakat serta meneguhkan eksistensi dan kepercayaan kepada masyarakat luas. Majelis Dzikir dan Shalawat Birrul Walidain bersama kyai kampung secara konsisten menjaga marwah Islam Indonesia melalui arus bawah dengan metode dakwah kultural yang ujungnya terbentuk kesadaran kultural (Habib, 2018). Terlebih, saat ini bangsa Indonesia dihadapkan pada dua persoalan utama, yaitu: pertama, gerakan Islam trans-nasional yang membawa ideologi kekerasan, khilafah Islamiyah sebagai bentuk ekstrim kanan. Di sisi lain munculnya gerakan ekstrim kiri yang membawa liberalisme agama dapat menggerus kehidupan beragama dan berbangsa. Kedua, kuatnya arus globalisasi, dan pop culture dapat berdampak negatif pada kehidupan sosial keagamaan masyarakat, termasuk Karangwuni Karanganyar.

Secara umum, gerakan Islam trans-nasional serta modernisasi dengan gerbongnya berdampak pada kehidupan masyarakat pedesaan, salah satunya tercerabutnya mereka dari akar budaya yang menyebabkan krisis spiritualitas yang menyebabkan rusaknya moralitas bangsa. Majelis taklim sebagai garda terdepan dalam memberdayakan masyarakat melalui pendidikan keagamaan di tingkatan keluarga menjadi basis dasar dalam menguatkan keislaman dan keindonesiaan. Melalui berbagai kegiatan, majelis tersebut membangun ketahanan budaya dengan penguatan spiritualitas yang mencerahkan sebagai sarana pendidikan ruhani (tarbiyah al ruhaniyah) untuk pengendalian diri di tengah kehidupan yang hedonistik. Komunitas keagamaan seperti majelis taklim dapat digunakan sebagai wadah pemberdayaan komunitas dalam aspek sosial dan ekonomi (Pabbajah, 2020). Tujuan penelitian ini adalah mengulas majelis taklim Majelis Dzikir dan Shalawat Birrul Walidain menjadi media yang efektif dalam membentuk karakter dan identitas jamaah yang toleran. Bagaimana majelis taklim tersebut sebagai gerakan kultural dan spiritualitas pencarian masyarakat pedesaan (rural sufism) mampu menjadi pilar dalam membangun teologi kemanusiaan dan kesalehan sosial berdasarkan nilainilai Aswaja seperti tawāsut , tasamuh, dan tawäzun di tengah pluralitas bangsa?

Penelitian mengenai majelis dzikir dan shalawat Birrul Walidain Karangmojo Tasikmadu Karanganyar adalah penelitian kualitatif deskriptif. Penelitian ini diharapkan mampu mengungkap makna yang ada dari pemikiran dan tindakan dari objek penelitian (Strauss, Anselm dan Corbin, 2007). Selanjutnya agar penyampaian mengenai penelitian ini bisa lebih terbuka dan natural, dikemukakan dengan model deskriptif analitis. Penelitian ini menggunakan pendekatan sosiologi agama. Agama dipandang sebagai "sebagai perbuatan" (religion in action), fakta sosial (social fact) sesuatu yang nyata dan dapat diamati yang mempengaruhi perilaku masyarakat (Sodik, 2006). Agama dinilai sebagai sistem kepercayaan yang diwujudkan dalam perilaku sosial tertentu (Tischler, 1990; Connolly, 2002). Pendekatan sosiologi agama mempelajari aspek sosial agama (Adibah, 2017). Pengumpulan data dilakukan melalui tiga cara (Sugiyono, 2016):pertama, observasi langsung pada majelis dzikir dan shalawat Birrul Walidain. Kedua, wawancara mendalam dengan tokoh majelis taklim ini, jamaah, dan pihak-pihak yang berkepentingan. Pengumpulan data pertama dan kedua merupakan sumber primer dalam penelitian ini. Sedangkan sumber ketiga, diperoleh melalui catatan dokumen baik yang bersumber dari berbagai referensi baik buku ilmiah, artikel jurnal, disertasi maupun tesis. Adapun analisis data dilakukan melalui model analisis interaktif yang meliputi: reduksi data, penyampaian data, dan penarikan kesimpulan (Saidi, 2004; Faishol, 2007). Kesimpulan yang didapatkan diuji kebenarannya dan validitasnya dengan dua cara, yaitu triangulasi data dan review informan.

\section{Birrul Walidain, Rural Sufism, dan Spiritualitas Masyarakat Pedesaan}

Majelis dzikir dan shalawat Birrul Walidain merupakan gerakan sosial keagamaan dalam bentuk pengajian yang aktif memberdayakan dan mengembangkan spiritualitas masyarakat pedesaan. Birrul Walidain merupakan tempat sebagai sarana untuk pencarian spiritualitas masyarakat desa (rural sufism). Rural sufsim merupakan konotasi urban sufism, istilah untuk menyebut fenomena gerakan sufisme di wilayah pinggiran atau pedesaan dan dilakukan kalangan Islam tradisional (Mibtadin, 2020). Gerakan spiritual ini menekankan tausiyah keagamaan, dzikir, shalawat, dan doa (Al Faruq, 2020). Sebagai rural sufism, majelis ini merupakan pencarian spiritualitas (spirituality seekers) jamaah Masjid Al-Muttaqien Karangmojo Tasikmadu. Majelis dzikir dan shalawat Birrul Walidain bertujuan untuk melatih kejiwaan yang bercorak post-sufistik sebagai bagian dari gerakan spiritual Islam 
tradisional dengan amaliah tertentu. Majelis Taklim ini diharapkan mampu menguatkan basis keimanan, mengentaskan kekeringan jiwa, dan kedahagaan spiritual masyarakat Karangmojo di tengah permasalahan sosial seperti kesulitan ekonomi, pendidikan keagamaan, dan radikalisme agama. Menurut Anas Aijudin (2020), sesepuh majelis ini, kehadiran majelis ini di tengah masyarakat memiliki dua peran strategis, sebagai ekspresi keagamaan dan penguatan narasi kebangsaan.

Majelis dzikir dan shalawat Birrul Walidain berdiri tahun 2005 dirintis Rochmadi sebagai untuk wadah aktivitas sosial keagamaan jamaah Masjid Al-Muttaqien Karangwuni Karangmojo Tasikmadu. Majelis taklim ini mempunyai izin operasional Kemenag Kabupaten Karanganyar dengan No. 191 Tahun 2018 tetanggal 07 September 2018, dan No statistik majelis taklim 431233130001 yang berlaku hingga tahun 2023. Tujuan majelis ini adalah peningkatan spiritualitas dan pemahaman keagamaan jamaah sehingga mereka tidak mudah hanyut dalam arus Islam trans-nasional. Majelis taklim ini diketuai Anas Aijudin, seorang intelektual muda NU yang aktif sebagai tokoh penggerak moderasi beragama di Surakarta, sehingga wajar jika majelis ini semakin gencar mewacanakan Islam moderat disetiap tausiyah keagamaan. Dengan kapasitasnya, Anas mendorong Birrul Walidain lebih progresif dan berorientasi pada gerakan sosial untuk pemberdayaan jamaah dan masyarakat. Kehadiran majelis taklim ini menjadi penting di saat jamaah menghadapi gelombang perubahan sosial, keagamaan, dan budaya yang menuntut sikap tegas dalam meresponnya. Keberadaan majelis taklim ini juga menjadi "benteng" keberagamaan jamaah dan masyarakat dari Islamic pop dan gerakan Islam trans-nasional yang memberangus tradisi Islam Nusantara, budaya, dan local wisdom yang mengandung nilai-nilai keharmonisan sosial (Wawancara dengan Aijudin, 07/10/2020).

Keberadaan majelis taklim ini menjadi ruang publik bagi jamaah dan masyarakat Karangwuni untuk mengekspresikan spiritualitas keberagamaannya. Muhsin Jamil menilai, gejala kebangkitan sufisme sebagai bentuk kebangkitan agama baru (new religion) yang disebabkan krisis spiritual serta radikalisme keagamaan yang marak. Jamil menambahkan masyarakat merasakan adanya kekeringan jiwa dengan pola keberagamaan yang legalistik dan kaku sehingga mendorong mereka mencari bentuk atau alternatif lain cara beragama lain yang humanis dan toleran (Jamil, 2013). Majelis dzikir dan shalawat Birrul Walidain menjadi media untuk mendorong kebangkitan sufisme pedesaan sehingga menjadi fenomena keberagamaan yang menjadi ruang spiritualitas pencarian melalui pengajian, dzikir dan shalawat, berjanjen, manaqib, dan tahllil kalangan Islam tradisional di perkampungan.

Menurut (Syukur \& Muhaya, 2015), model pencarian spiritualitas pedesaan dengan istilah sufisme pada tradisi rendah atau tradisi kampung yang dilawankan dengan tradisi kosmopolitan menurut Gellner seperti dikutip Haryanto (2012) yakni varian legalistik yang dipegang kaum ulama (Haryanto, 2012). Awalnya Gellner seperti dikutip Haryanto (2012) menyakini sufisme menjadi elemen yang pertama kali tergusur modernitas, sebab sufism bagian dari tradisi agama pedesaan. Tesis Gellner terpatahkan tidak terbukti sebab eksistensi sufisme sebagai bagian dari tradisi agama pedesaan masih tetap eksis, bahkan menjamur di berbagai daerah. Tradisi tersebut digawangi Islam tradisional dengan menggerakan masyarakat bawah untuk membentuk enclave-enclave keagamaan dalam bentuk paguyuban spiritual seperti pengajian, majelis taklim, majelis dzikir-shalawat, tahlil, dan manaqib untuk penguatan moralitas masyarakat pedesaan. Perkembangan rural sufism cukup menggembirakan sebagai bentuk ekspresi keberagamaan yang menjadi wadah bagi pengembangan spiritualitas masyarakat akar rumput.

Menurut Howell (2001) sebagaimana dikutip (Anis, 2013), tradisi sufisme dalam Islam tidak serta merta mati tetapi bertransformasi sesuai dengan setting ruang dan waktu yang mengalami perubahan dalam bentuk dan gerakannya dengan tendensi baru dalam tradisi sufisme dikenal sebagai sufisme kota (urban sufism). Basis sosial sufisme kota adalah kalangan masyarakat menengah yang memiliki tingkat pendidikan, ekonomi, dan sosial yang lebih baik (Rosidin, 2014). Urban sufism bagi masyarakat kota mampu membantu mereka dalam mendapatkan ketenangan hati karena ketidakpuasannya pada praktik keagamaan puritan yang bercorak formalisme dan tidak menyentuh aspek spiritualitas. Menurut Naisbit, fenomena urban sufism dikenal sebagai "high-tech, high touch". Urban sufism memilih ruang dan aktivitas keagamaan yang berbeda dengan rural sufism atau tasawuf konvensional yang kebanyakan berasal dari kalangan pedesaan. 
Fenomena kebangkitan spiritulitas sebagaimana dikemukakan Stanislov (1996) seperti dikutip (Putra, 2013) adalah bahwa adanya persoalan psikologis eksistensialis keagamaan, keterasingan dan krisis spiritual dalam masyarakat modern. Krisis tersebut adalah terkoyaknya ruang spiritual diri setiap individu terfragmentasi secara psikologi-spiritual yang berakibat pada terasingnya diri (Mibtadin, 2020). Keterasingan ini mendorong mereka mencari ketenangan hati. Melalui pengajian majelis taklim, mereka menemukan kembali makna eksistensinya sebagai manusia yang utuh dengan segala fitrah kemanusiaannya. Menurut Anas Aijudin (2020), ada beberapa faktor yang mendorong maraknya model rural sufism berkembang di masyarakat pedesaan, yakni: pertama, melalui majelis dzikir dan shalawat seperti Birrul Walidain menjadi wahana pencarian makna hidup sekaligus terapi psikologis untuk menyelesaikan persoalan kejiwaan agar tidak kering dari spiritualitas. Kedua, majelis dzikir dan shalawat dapat menjadi media sosialisasi untuk menguatkan ar-ruh al-insaniyah, al-Islamiyah, al-wathoniyah dan ar-ruh ta'adudiyah sekaligus mendapatkan pencerahan intelektual.

Majelis dzikir dan shalawat Birrul Walidain merupakan pengajian rutin setiap malam Jumat legi bertempat di kediaman Anas Aijudin depan Masjid Al-Muttaqien Karangwuni. Jamaah Birrul Walidain terdiri dari 200 sampai 250-an orang yang secara konsisten mengikuti pengajian. Peran aktif dari pengurus Birrul Walidain mendorong jamaah untuk mengekspresikan keberagamaan melalui pengajian, shalawatan, serta mau'idhoh khazanah dari kyai yang didatangkan. Menurut Anas Aijudin (2020), jamaah pengajian majelis taklim ini terdiri dari santri, muslimat, dan masyarakat umum, sehingga menjadi fenomena positif bagi perkembangan dakwah di Karangmojo karena merangkul semua komunitas, mereka duduk bersama dalam mengamalkan ajaran agama tanpa dibedakan.

Keberadaan Majelis dzikir dan shalawat Birrul Walidain menjadikan masyarakat Karangwuni mulai mengenal dan mengkaji kembali turaś serta pengetahuan keagamaan tradisional agar sejalan dengan realitas kekinian. Menurut Anas Aijudin, majelis ini menjadi lokomotif bagi jamaah agar terbuka terhadap wacana keagamaan baru yang disesuaikan dengan budaya lokal setempat. Birrul Walidain menjadi media untuk jamaah dan masyarakat Karangwuni agar memiliki cara berpikir kritis dengan mengedepankan Aswaja an-Nahdliyah sebagai manhaj al-fikr yang mengedepankan tawāsut, tasamuh, dan tawäzun. Sebagai lembaga pendidikan agama, majelis taklim ini menjadi benteng dalam menjaga keutuhan berbangsa dan beragama dengan menempatkan moral sebagai landasan kehidupan sosial yang mengajarkan sikap saling menghormati dan toleran pada kelompok lainnya. Islam dipahami sebagai etika sosial yakni bentuk kepedulian terhadap moralitas dan kebenaran demi terciptanya kerukunan, keadilan dan kesejahteraan sosial. Sebab, kesejahteraan spiritual sangat dibutuhkan untuk mewujudkan keharmonisan sosial. Melalui majelis taklim ini, Anas Aijudin fokus menguatkan jamaah agar menjadi agen perubahan untuk basis sosialnya masing-masing (Aijudin, 07/10/2020).

Menurut Anas Aijudin (2020), hanya kyai dan sesepuh bersentuhan langsung dengan masyarakat sehingga bisa memahami bahasa dan berkomunikasi dengan mereka untuk menyampaikan pentingnya nilai dasar Islam sebagai agama damai, ramah, dan toleran. Tidak penting bagaimana cara dan metodenya, yang utama adalah pesan mengenai keislaman moderat sampai pada masyarakat. NU memiliki tugas berkaitan dengan masyarakat, yaitu: pertama, pembangunan mental spiritual, pembentukan kepribadian, dan karakter masyarakat yang memiliki tanggungjawab kepada Tuhan dan manusia. Kedua, penguatan pembangunan bangsa (nation building) dengan penanaman cinta tanah air, penegasan pada Pancasila, NKRI, dan UUD 1945 (Siraj, 2014). Dengan Birrul Walidain diharapkan bisa mendorong kesadaran jamaah dan masyarakat Karangwuni agar terbuka, menggerakan budaya masyarakat sipil, serta mendorong Islam sebagai praktik sosial yang terejawantahkan dalam harmonisasi kehidupan yang majemuk.

Seperti majelis taklim lainnya, majelis taklim ini mendorong corak beragama jamaahnya pada akhlak yang mulia. Dalam tasawuf dikenal dengan takhallqu bi ahlaqiyyah, tauhid sebagai nilai dasar yang mengarahkan pada prinsip tepo sliro, saling menghormati, dan terbuka. Keberadaan majelis taklim ini menjadi media pembentukan karakter kepribadian jamaah agar mencapai tingkatan manusia bermartabat dengan tabiat yang baik dan menegasikan sifat-sifat jelek dan kekerasan atas nama agama. Karena itu, majelis taklim ini dalam aktivitas keagamaannya melakukan dzikir, shalawat, dan tausiyah, 
jamaah bisa merasakan kehadiran Tuhan sehingga kedamaian hati dan ketenangan hidup bisa dirasakan. Di sisi lain, majelis taklim ini menjadi kekuatan Islam mainstream untuk melakukan perlawanan kultural terhadap Islam trans-nasional yang cenderung menggunakan kekerasan serta memberangus budaya lokal yang dinilai tidak sejalan dengan nafas agama. Seperti tradisi selamatan, haul, talqin, tahlilan, yasinan, manaqib, ziarah kubur, sekaten, puji-pujian, shalawatan, berzanji dan budaya Islam Nusantara lainnya. Keberadaan majelis taklim ini ingin menunjukan Islam adalah agama damai, rahmatan lil'alamin, dan menolak kekerasan berlabel agama. Sebab kekerasan adalah bentuk pengingkaran pada agama itu sendiri karena dapat mereduksi dan merusak nilai-nilai universal yang dikandung agama (Aijudin, 07/10/2020).

Rural sufism, Birrul Walidain merupakan upaya untuk meneguhkan Islam Nusantara berangkat dari prinsip al-Islam shalih likuli zaman wa al makan, maka Islam berkembang bersifat akomodatif terhadap budaya lokal dimana ia hadir. Islam Nusantara bisa lebih berkembang lagi karena dengan nilai-nilai luhur budaya lokal yang penuh kearifa yang menjadi pandangan hidup (worldview) masyarakat Karangwuni (Aijudin, 2020). Melalui Islam Nusantara mendorong tampilnya agama yang humanis, moderat, dan mengakomodir budaya lokal. Pilihan Birrul Walidain untuk membumikan nilai-nilai keislaman melalui pendekatan budaya diharapkan memiliki "daya hidup" (life force) di tengah masyarakat. Berbagai media yang digunakan seperti wejangan keagamaan, kirim doa, syi'iran, dzikir, dan shalawat adalah bentuk kecerdasan spiritual pengurus Birrul Walidain dalam membumikan nilai-nilai keislaman di tengah masyarakat yang terus dipraktikkan warga Nahdliyin Karangwuni.

Melalui majelis dzikir dan shalawat Birrul Walidain, kyai lokal yang memberikan maudhoh khasanah menanamkan kerukunan kepada jamaahnya. Spiritualitas dan kesalehan sosial inilah tujuan akhir Birrul Walidain sebagai pengejawantahan dari sense of oneness mendorong sikap keberagamaan jamaah pada beragama yang kritis. Majelis taklim ini merupakan proses pencarian spiritualitas menuju Allah, dengan pola hidup yang dinamis yang menuntut kerjasama antar jamaah dalam jiwa ketuhanan dan kebaikan melalui jalan yang benar (sirat al-mustaqim). Jamaah diharapkan bisa menjadi religious person, sosok pribadi yang religius dan person of mature faith, pribadi yang matang imannya. Pribadi yang mampu menafsirkan keseluruhan dunia dan menciptakan "pandangan dunia" (mabda al-hayah) secara berturut-turut. Birrul Walidain melakukan penguatan nilai-nilai keagamaan dengan mengajarkan nilai-nilai dasar dari Islam seperti kesederhanaan, kejujuran, keikhlasan, kebersamaan, persatuan, ketulusan, dan kemandirian, yang dengan sikap ini bisa mendorong pada kehidupan harmonis, damai, dan bisa saling menjaga antara satu dengan lainnya. Nilai-nilai ini bisa dipraktekkan dalam prilaku kehidupan sehari-hari jama'ah ketika mereka ada di tengah masyarakat sehingga Islam menjadi agama yang dinamis, progresif, dan tarnsformatif (Aijudin, 2018).

Kutipan di atas menjadi basis moralitas untuk pengembangan kedewasaan beragama jamaah Majelis dzikir dan shalawat Birrul Walidain, sebab majelis ini adalah spiritualitas pencarian masyarakat pedesaan dengan segala keterbatasan ekonomi, pendidikan, informasi, dan budaya untuk internalisasi nilai-nilai keagamaan. Keberadaan Birrul Walidain mencoba melengkapi dimensi spiritualitas masyarakat Karangwuni yang selama ini kurang mendapatkan perhatian. Birrul Walidain merupakan media untuk belajar mengamalkan ajaan tasaswuf yang digunakan untuk pembersihan hati dan jiwa jamaah serta media mendekatkan diri kepada Allah sekaligus memperbaiki moralitas masyarakat. Sejauh ini, majelis taklim ini menjadi ruang pengkaderan "ulama lokal" Karangwuni dimana setiap acara pengajian yang memberikan tausyiah keagamaan adalah orang lokal yang dijadwal secara bergiliran seperti Anas Aijudin, Sahal, Zahro, Wardi, Narso, Suharto, Abdussomad, dan Syamsuddin. Majelis taklim ini menjadi bagian dari gerbong besar Islam Nusantara, yakni diskursus dan tipologi Islam yang dikembangkan Pengurus Besar Nahdlatul Ulama (PBNU). Model pengkajian Islam melalui lembaga keagamaan, majelis taklim, majelis dzikir dan shalawat, serta pengajian merupakan cara pandang baru dalam mengenal Islam lebih mendalam. Eksistensi Birrul Walidain dengan penguatan Aswaja di tengah masyarakat merupakan usaha membuka jalan untuk mengembangkan dan membentangkan Islam Nusantara sebagai discourse sekaligus rujukan 
pengetahuan bagi Islam yang toleran, ramah, dan moderat sehingga bisa menjadi inspirasi bagi masyarakat luas.

\section{Majelis Dzikir dan Shalawat Birrul Walidain, Ruh Keagamaan dan Islam Moderat}

Gerakan sosial keagamaan, majelis dzikir dan shalawat Birrul Walidain merupakan bentuk penjagaan pada tradisi yang diwariskan para ulama terdahulu untuk penguatan moralitas masyarakat. Tujuan utama majelis taklim ini adalah untuk menggugah kembali jamaah dan masyarakat Karangwuni Karangmojo terhadap pentingnya mengembangkan akhlak mulia, hidup rukun berdampingan, dan sikap menghargai sesama berdasarkan nurani dan kebeningan hati. Selain itu, Birrul Walidain juga diorientasikan guna terciptanya kesadaran masyarakat tentang makna pentingnya hidup bersama dalam suasana damai, yang dimulai diri sendiri, yaitu kembali menyadari pentingnya upaya mensucikan jiwa untuk keseimbangan hidup. Hal terpenting dari majelis taklim ini adalah menggerakkan kembali segala potensi spiritual yang dimiliki jamaah untuk kemanfaatan yang optimal bagi bangsa dan seluruh insan sebagai solusi dari masalah kemanusiaan kontemporer (Aijudin, 2020). Rural sufism, majelis taklim ini menjadi bagian kecil dari upaya NU untuk menggerakan peradaban sekaligus asy-syuhud aś-Saqafi masyarakat dalam membangun dan menyangga kerukunan dan moralitas bangsa agar warganya berkarakter baik sebagai bentuk rahmatan lil 'alamin. Kekuatan NU bertumpu pada tiga hal, yaitu: pertama, paham Aswaja an-Nahdliyah yang melahirkan wacana Islam moderat; kedua, nilai, tradisi, dan lembaga budaya seperti pesantren dan jaringan thariqat; dan ketiga, jaringan struktur sebagai infrastruktur organisasi yang tersebar di seluruh pelosok Nusantara (Siraj, 2013). Ketiga kekuatan itulah yang menjadi tumpuan majelis taklim ini untuk menggerakan tradisi, menciptakan keharmonisan sosial, dan mendorong kerukunan di tengah masyarakat.

Majelis dzikir dan shalawat Birrul Walidain berupaya membumikan nilai-nilai keislaman moderat serta mendapatkan kepercayaan masyarakat Karangwuni, sehingga menjadi pandangan hidupnya. Hal ini tepat di tengah munculnya ekstrim ideologi kanan-kiri, ekstrim gaya hidup, Islamic pop, dan majelis taklim ini tetap mengambil jalan tengah dengan prinsip tawāsuț, tasamuh, dan tawāzun. Fenomena yang berkembang di tengah masyarakat Karanganyar adalah persoalan kemanusiaan berupa "gesekan" sosial yang sering kali muncul akibat krisis keagamaan Sikap eksklusif ini berdasarkan pada anggapan pemahaman keagamaan mereka yang paling benar, paling shahih, dan sesuai dengan Alqur'an dan Sunnah. Sehingga orang di luar pemahaman mereka adalah salah serta "harus diIslamkan kembali" dengan jalan mengikuti apa yang mereka pahami tentang doktrin ajaran agama tersebut. Dalam gerakannya, kelompok ini seringkali melakukan dengan jalan radikal atau tindak kekerasan yang mengatasnamakan Tuhan (Langham \& Kurtz, 1996). Sikap ini juga sering diikuti sikap anti dialogis yang menolak menggunakan cara beradab dengan jalan dialog untuk menemukan solusi bersama.

Majelis taklim ini menampilkan cara beragama yang inklusif, berimbang antara dimensi bayani, burhani, dan 'irfani seperti konsepsi Islam Nusantara yang mengedepankan Islam moderat. Keseimbangan epistemologi tersebut sebagai upaya membangun karakter masyarakat melalui penguatan keimanan (person of mature faith). Untuk hal tersebut, majelis taklim ini mengedepankan prinsip tawāsuț, tasamuh, dan tawāzun yang mendorong jamaahnya out of the box tidak terkotak dengan nalar ideologis yang hitam putih, benar salah saja. majelis taklim ini juga mendorong keseimbangan beragama secara vertikal (habl min Allah) dan horisontal (habl min nass), memuliakan Tuhan dengan memuliakan manusia dengan segala kemanusiaannya sebagai manifestasi dari keimanan. Prinsip tersebut terwujudkan adanya spiritualitas kemanusiaan yang mendorong the seed of moderate Muslims serta pengembangan kultur sipil. Secara prinsip, kultur sipil adalah nilai, norma, dan moral guide di masyarakat yang menghormati berbagai aspek pokok dalam wacana demokrasi, toleransi, kesetaraan, pluralisme, HAM, penghargaan pada minoritas, dan kemandirian. Nilai tawāsuț, tasamuh, dan tawāzun yang dikembangkan majelis taklim ini mendorong Islam berada pada ranah civil society untuk moral reasoning bagi pengembangan masyarakat Karangwuni. Majelis dzikir dan shalawat Birrul Walidain mendorong Islam berpartisipasi aktif dalam menyelesaikan persoalan kemanusiaan dan kemasyarakatan tanpa harus mendiskriminasi agama lain atau kelompok sosial yang berbeda (Aijudin, 
2020). Jika jamaah merasa dekat dengan Tuhan, maka akan merasa malu ketika melakukan perbuatan yang tidak sesuai dengan norma agama, serta menjauhi sikap yang berlebihan dalam beragama. Majelis dzikir dan shalawat Birrul Walidain berusaha menampilkan agama sesuai fitrahnya yang membawa pesan suci perdamaian sehingga terwujud kemanusiaan universal. Jamaah Birrul Walidain diharapkan bisa melahirkan sikap dan tindakan kemanusiaan yang positif karena hal tersebut bisa menjadi sumber makna dan kebijakan. Melalui majelis taklim ini berusaha menanamkan Islam pada jamaahnya yang mampu menggerakan aksi-aksi kemanusiaan yang berbudaya dan beradab.

Melalui tausiyah yang mencerahkan menjadi common values dan basis membangun dialog kemanusiaan yang kondusif dan prospektif (Arisandy \& Eenfryanti, 2019), jamaahnya memiliki cara pandang yang toleran dan peaceful karena ini sangat diperlukan untuk menjaga dinamika keberagamaan agar tidak tenggelam pada pertikaian, kekerasan atas nama agama, dan konflik sosial. Birrul Walidain melalui prinsip tawāsuț, tasamuh, dan tawāzun, Islam didorong terlibat aktif dalam persoalan publik, dan menjadi bagian dari dan berada di ranah masyarakat sipil. Di tengah kehidupan yang prinsip tersebut menampilkan Islam bukan sebagai agama yang eksklusif, tetapi membawa aspirasi masyarakat sipil yang bersifat universal, $\left(\mathrm{Na}^{\prime} \mathrm{im}, 1997\right)$ disebut "public reason." Islam dituntut untuk merumuskan tantangan universal kemanusiaan, seperti kemiskinan, kebodohan, kesenjangan ekonomi, dan yang lebih penting adalah penghargaan pada fitrah dasar kemanusiaan seperti kebebasan beragama, ekspresi budaya, dan minoritas (Abdain, 2014).

Pola pengembangan Islam sebagai public reason atau etika sosial dengan model majelis taklim ini menjadi media efektif guna melakukan evaluasi mengenai toleransi keberagamaan dengan jalan memotret Islam sebagai logical frame work untuk membangun teologi kemanusiaan yang responsif pada perubahan sosial. Teologi ini menekankan makna pentingnya spiritualitas baru, suatu sikap yang lebih mementingkan kesalehan sosial daripada kesalehan individual (Nopriyansa, 2020). Teologi ini bagian dari spiritualitas dipahami sebagai upaya menghidupkan dan menumbuhkan kembali elan profetik seperti yang tercermin dari para rasul pembawa risalah kenabian untuk mengangkat harkat dan martabat kemanusiaan.

Majelis dzikir dan shalawat Birrul Walidain sejauh ini sudah mengembangkan spiritualitas kemanusiaan yang mengedepankan model pembebasan hakiki, yakni pembebasan yang berakar dan terarah untuk penghargaan setinggi-tingginya kepada kehidupan sosial manusiawi. Menurut Gus Dur, pembebasan dari berbagai jerat dominasi penindasan, ketidakadilan, dan hegemoni yang diarahkan untuk kemanusiaan (A. Wahid, 2006). Semua agama menyimpan kekuatan pembebasan, tetapi dunia juga mempunyai mekanisme perubahan sendiri sehingga berbahaya ketika agama diturunkan pada teknik dan penentu pembebasan, karena agama bisa menjadi kekuasaan yang menindas atas nama Tuhan (M. Wahid, 2010). Menurut Asghar, hakikat kehadiran Islam adalah untuk membebaskan manusia dari segala diskriminasi, ketidakadilan, dan pelanggaran harkat kemanusian (Engineer, 2004). Melalui Birrul Walidain diharapkan terbangunnya kesadaran yang menginginkan implementasi Islam sebagai agama rahmatan lil'alamin tanpa melihat latar belakang suku, etnis, bahasa, dan gender. Islam bukan ditempatkan sebagai isu sentral, tetapi memposisikan Islam sebagai ruh untuk membangun penghormatan pada ar-ruh al-insaniyah (Aijudin, 2020).

Sejauh ini, warna keislaman yang dikembangkan majelis taklim ini sejalan dengan pandangan Abdurrahman Wahid, dimana Islam harus dilihat dan didekati dari fungsinya sebagai pandangan hidup yang mengedepankan kesejahteraan masyarakat, baik masyarakat Islam maupun bukan (Wahid Abdurrahman, 1989). Berangkat dari paradigma universalisme kosmopolitanisme Islam yang mengedepankan kepedulian yang besar pada unsur utama dari kemanusiaan seperti keadilan, HAM, pluralisme, dan demokrasi (A. Wahid, 1994). Majelis dzikir dan shalawat Birrul Walidain mengembangkan spiritualitas kemanusiaan ini mendorong terwujudnya kemashlahatan dalam kehidupan seperti yang terangkum al-maqashid al-syariah yang mencakup al-kuliyat al-khamsah: hifdz aldin, hifdz an-nafs, hifdz al-'aql, hifdz an-nash, serta hifdz al-amwal. Wacana spiritualitas baru ini menjadi penting sebagai landasan "ideologis" untuk membangun masyarakat yang toleran di tengah kemajemukan bangsa berdasarkan penghargaan atas nilai-nilai kemanusiaan universal. Rumusan spiritualitas baru tersebut disandarkan pada pemahamannya yang kuat pada ajaran Islam serta 
diarahkan untuk toleransi dan keharmonisan sosial (Barton, 1999). Spiritualitas baru ini mendorong Islam tidak hanya dipahami dalam aspek belief, tetapi lebih pada practice untuk kemanusiaan universal (Dahlan, 2019).

Model spiritualitas baru majelis taklim ini bersifat beyond symbols yang disandarkan pada gagasan keislamannya yang rahmatan lil'alamin. Nilai universal, toleran, dan moderat dalam Islam yang dikembangkan majelis tersebut adalah muatan dari ajaran Islam yang mengedepankan kepedulian pada moralitras dan kemanusiaan. Dengan landasan semangat keikhlasan dan kejujuran dari pengelolanya, spiritualitas baru yang dikembangkan majelis taklim ini bisa memiliki "daya hidup" dalam berbagai ruang kehidupan berbangsa terutama masyarakat Karangwuni Karanganyar. Spiritualitas ini menginginkan Islam tidak menampilkan wajahnya yang simbolik, tetapi Islam harus mengintegrasikan kegiatannya dalam aktivitas kebangsaan secara keseluruhan (Wahid, 1999). Spiritualitas kemanusiaan dapat dipraksiskan dalam konteks yang lebih nyata sebagai teologi kemanusiaan untuk pemberberdayaan dan peningkatan kualitas kehidupan masyarakat Karangwuni dalam upaya transformasi sosial keagamaan (Huda, 2019).

Majelis dzikir dan shalawat Birrul Walidain secara prinsip mendorong spiritualitas kemanusiaan dengan "teologi ramah" berdasarkan prinsip tawāsuț , tasamuh, dan tawäzun serta menempatkan Islam sebagai pandangan hidup (worldview) yang diturunkan pada nilai utama seperti toleransi dan kerukunan. Majelis taklim ini Islam dengan damai dan beradab untuk membangun landasan spiritualitas personal sekaligus membangun etika sosial bagi jamaahnya agar tercipta keharmonisan sosial di tengah masyarakat Karangwuni, Karangmojo Tasikmadu Karanganyar. Hal ini sejalan pandangan Said Aqil Siraj (2013), "Nahnu ash-habul haqq, haqqudini wal haqqul ijtimā'i," kami kelompok yang benar, benar dalam beragama dan benar dalam bermasyarakat-bernegara. Sebab, dalam pengembangan Islam, NU menggunakan prinsip "al-amnu qobla imān" menciptakan keharmonisan sebelum mengajarkan keimanan serta "al-mua'asyaratu qabla 'aqidah" membangun komunikasi sebelum mengenalkan akidah (Siraj, 2013).

\section{Majelis Dzikir dan Shalawat Birrul Walidain, Character Building, dan Pengembangan Masyarakat}

Sebagai majelis taklim, majelis dzikir dan shalawat Birrul Walidain mengembangkan Aswaja anNahdliyah yang memiliki peran besar dalam membangun masyarakat, bangsa dan negara yang maju, beradab, dan berkarakter mulia. Prinsip tersebut terumuskan dalam liyatafaqqahu fiddin dan liyundziru qaumahum. Menurut Said Aqil Siraj (2013), berkaitan dengan masyarakat, NU memiliki beberapa aspek yaitu: pertama, pembentukan kepribadian atau karakter masyarakat (character building) agar masyarakat memiliki tanggungjawab pada Tuhan, masyarakat, dan negara. Kedua, nation building melaui pembentukan karakter sebagai modal dasar bagi pembangunan negara (state building) sehingga terwujud kepribadian yang kokoh, punya identitas nasional, dan beradab. Ketiga, membangun sikap kritis (criticism building) terhadap pemerintah berdasarkan prinsip 'amar makruf nahi munkar berdasarkan pertimbangan etis dan bukan politis (Siraj, 2013). Berangkat dari kutipan di atas, Birrul Walidain menekankan pentingnya character building dan nation building sebagai manhaj al-fikr dan titik berangkat dalam menyelesaikan persoalan kebangsaan, seperti kemrosotan moral dan lunturnya karakter serta identitas bangsa. Tujuan akhir dari majelis taklim ini adalah terbentuknya masyarakat yang beradab dan berbudaya dengan landasan hubul wathān minal imān seperti yang dilantunkan di setiap akhir acara pengajiannya (Aijudin, 2020).

Majelis dzikir dan shalawat Birrul Walidain menjadi salah satu media untuk character builidng dan state building yang dilakukan melalui pemberdayaan spiritualitas masyarakat pedesaan seperti pengajian, shalawatan, dan tradisi keagamaan lainnya. Menurut Anas Aijudin (2020), dua amanat yang diemban Birrul Walidain adalah amanat al-diniyyah dan al-wathāniyyah dengan membangun karakter, kepribadian, dan jati diri bangsa melalui pemberdayaan jamaah agar memiliki konstribusi untuk peningkatan keimanan, penguatan sosial dan pengembangan civil society di Indonesia dan ecara intensif pada perubahan sosial keagamaan. Karena itu, majelis taklim ini secara aktif hak-hak warga negara, hak politik, dan hak sosial. 
Sebagai gerakan kultural, majelis taklim ini menjadi kekuatan civil society untuk mendorong tumbuh berkembangnya kemandirian pengetahuan masyarakat dalam bidang kebangsaan dan keagamaan. Dalam konteks ini, majelis taklim ini memberikan batasan etika dan moral politik kebangsaan. Birrul Walidain juga menanamkan kesadaran kritis pada jamaah dengan memposisikan Islam sebagai kekuatan moral (moral force) dalam proses perubahan sosial yang dilakukan melalui bhakti sosial dan pemberdayaan ekonomi ternak lele. Ada beberapa strategi Birrul Walidain untuk pemberdayaan jamaahnya, yaitu: pertama, melakukan pemetaan atas permasalahan jamaah dan berbagai potensi yang ada di masyarakat sebagai basis dari kekuasaan civil society yang akan dikembangkan. Kedua, menggerakan potensi jamaah sesuai dengan bidangnya. Ketiga, ke depan, semua jamaah mempunyai kapasitas kemandirian (Nugraha, 2018b). Fokus pemberdayaan masyarakat majelis taklim ini adalah untuk pengembangan pendidikan keagamaan yang moderat, dakwah yang merangkul, pendidikan keagamaan, isu-isu kebangsaan, dan penguatan potensi lokal.

Dalam setiap pengajiannya, majelis taklim ini menekankan pada dua hal, yaitu: pertama, Islam sebagai sumber dan visi moralitas. Sejauh ini, Islam sebagai sumber konflik serta hanya penjaga moralitas manusia semata, dan jika fungsi agama hanya pada aspek ini akan mematikan inisiatif dan kreativitas umat Islam itu sendiri. Pada titik ini, majelis taklim ini mendorong Islam menjadi agama yang lebih dinamis dan mampu berperan dalam pergulatan kehidupan masyarakat. Kedua, Islam sebagai pemberi rasa damai, mempunyai fungsi yang penting dalam menunjang proses keadaban masyarakat. Rasa damai muncul dari keyakinan bahwa Tuhan merupakan ukuran keselarasan dunia, kebenaran agama bersifat eksplisit berkaitan dengan nilai-nilai. Dengan pendekatan ini, mendorong umat beragama untuk saling terbuka dan saling belajar satu dengan yang lain, sehingga Islam menjadi agama yang bermakna bagi kehidupan (Mibtadin, 2018).

Bermodalkan dua nilai tersebut, majelis dzikir dan shalawat Birrul Walidain memposisikan Islam sebagai etika sosial sehingga menjadi semangat (ar-ruh, spirit) dalam melakukan transformasi sosial keagamaan sebagai landasan membangun masyarakat yang damai, toleran, beradab dan menghargai perbedaan. Dengan demikian, majelis tersebut memiliki legitimasi sekaligus sumber perubahan sosial keagamaan yang mengakar kuat dalam kehidupan masyarakat Karangwuni Karangmojo. Dengan modal sosial ini, majelis taklim ini mampu memberi kontribusi penting dalam proses pembentukan karakter bangsa meskipun sekedar membangun kerukunan di tingkat lingkungannya. Karena itu, majelis taklim ini memiliki watak dinamis, progresif, dan akomodatif dalam mewujudkan cita rasa Islam Nusantara. Pengembangan nilai-nilai keislaman dan keindonesiaan majelis taklim ini pada dasarnya untuk memberikan modal sosial pada jamaah agar bisa menghargai perbedaan yang ada. Integrasi Birrul Walidain dengan masyarakat akhirnya membentuk suatu sistem yang diikat oleh nuansa ideologi keagamaan bercorak Ahl Sunnah wal-Jamaah an-Nahdliyah. Beberapa nilai-nilai keislaman yang dikembangkan Birrul Walidain seperti keikhlasan, kesabaran, dan kemanfaatan hidup ketika berada di tengah masyarakat.

Birrul Walidain menjadi media pendidikan keagamaan melalui mauidhoh khasanah dalam pengajiannya dengan cara tarbiyah al-ruhiyah dan tazkiyatun an-nafs diharapkan mampu memberikan kontribusi nyata untuk mewujudkan masyarakat yang beradab. Birrul Walidain memberikan kontribusi terkait dengan karakter-akhlak jamaah dengan tampilan Islam moderat, inklusif, dan khas Nusantara dengan memperhatikan kondisi objektif jamaah dan masyarakat Karangwuni yang majemuk. Tidak mengherankan jika jamaah Birrul Walidain memiliki pemahaman keagamaan yang terbuka dan toleran. Dengan pemahaman keagamaan ini, Birrul Walidain menampilkan Islam sebagai agama yang mengedepankan nilai persaudaraan al-uhuwah al diniyyah, wathaniyyah, insaniyyah, perdamaian, tolong-menolong, toleransi dalam hubungan antar sesamanya. Dengan Islam moderat, Birrul Walidain membentuk karakter dan identitas masyarakat dan bangsa yang santun, menghormati sesama, serta menghindarkan sikap eksklusif, intoleran, dan radikal karena bisa memecah kesatuan dan persatuan bangsa.

Majelis dzikir dan shalawat Birrul Walidain sebagai sebagai agen untuk mendorong perubahan sosial keagamaan dengan mengambil peran aktif dalam permasalahan yang ada di masyarakat. Paling tidak, majelis taklim ini menjadi media pendidikan keagamaan masyarakat Karangwuni sehingga 
memegang peranan penting sebagai penentu peningkatan kualitas spiritualitas jamaah. Birrul Walidain mengambil bagian terkecil dengan mencerdaskan kehidupan bangsa dengan jalan memberikan layanan pendidikan keagamaan dan dakwah secara maksimal kepada masyarakat Karangwuni. Pendidikan keagamaan Birrul Walidain pada dasarnya memberikan dua dimensi, yaitu keagamaan dan akademik yang dimaksudkan untuk merespons kebutuhan masyarakat. Birrul Walidain memiliki pririoritas dan tujuan, yakni mempelajari Islam tidak hanya sebagai basis epistemologis an sich, tetapi juga untuk diterapkan (applicated). Dengan demikian, tampilan Islam moderat tidak semata-mata untuk keperluan akademik, tetapi untuk peningkatan kualitas keimanan, ketakwaan, serta kehidupan masyarakat yang berakhlak dan beradab.

\section{Kesimpulan}

Majelis dzikir dan shalawat Birrul Walidain Karangwuni Karangmojo Tasikmadu Karanganyar merupakan media keagamaan sekaligus ruang publik bagi masyarakat desa untuk pemberdayaan spiritualitas, dakwah, dan pendidikan. Majelis taklim ini menjadi kegiatan rutinitas masyarakat Karangwuni Karangmojo terutama jamaah Masjid Al-Muttaqien yang menguatkan dua hal: al-amanah ad-diniyyah dan al-amanah al-wathaniyah. Praksis al-amanah ad-diniyah, majelis taklim ini menekankan dua aspek: pertama, sebagai media untuk pemberdayaan spiritualitas warga Karangwuni dalam bentuk little sufism untuk gerakan spiritualitas pencarian masyarakat pedesaan (rural Sufism). Kedua, sebagai public sphere, majelis taklim ini menjadi wadah ekspresi keberagamaan masyarakat, sekaligus lahan pendidikan keagamaan untuk pembentukan karakter, identitas dan moralitas bangsa. Bentuk alamanah al-wathaniyah, majelis taklim ini merupakan upaya mengembangkan gagasan Islam Nusantara dengan menampilkan Islam moderat dan menghargai lokalitas berdasarkan prinsip tawāsuț, tasamuh, dan tawāzun untuk memperkokoh ar-ruh diniyyah, wathaniyyah, dan insaniyyah. Bermodalkan Islam moderat, majelis dzikir dan shalawat Birrul Walidain membentuk karakter dan identitas bangsa yang santun, ramah, terbuka, dan saling menghormati sesama, serta menghindarkan dari pemahaman keagamaan yang intoleran dan radikal yang berbahaya karena bisa memecah persatuan bangsa. Birrul Walidain menjadi ruang pemberdayaan masyarakat Karangwuni yang didasarkan pada visi transformasi sosial, pembaharuan budaya, dan penyadaran hak dan kewajiaban bermasyarakat dalam kehidupan bernegara berdasarkan Aswaja an-Nahdliyah sehingga terwujud "Islam Nusantara" untuk penguatan kultur sipil, pengembangan karakter, dan identitas al-diniyyah dan al-wathaniyah.

\section{Ucapan Terima Kasih}

Penulis dalam kesempatan ini menyampaikan terima kasih dan memberikan penghargaan kepada pihak-pihak yang telah berkontribusi dalam penelitian ini, terutama kepada jamaah majelis dzikir dan shalawat Birrul Walidain Karangmojo, Tasikamdu Karanganyar. Selain itu, terima kasih disampaikan kepada sesepuh, kiai, jamaah, dan segenap masyarakat di wilayah tersebut. Kiranya tanpa mereka semua artikel ini tidak dapat terwujud di hadapan para pembaca.

\section{References}

Abdain. (2014). Peran Sistem Ekonomi Islam Dalam Menanggulangi. Jurnal Muamalah, IV(2), $15-26$. https://doi.org/https://doi.org/10.24256/m.v4i2.656

Abdullah, A. (2018). Wajah Toleransi Dan Perdamainan Dalam Kontestasi Historisitas. Religious: Jurnal Studi Agama-Agama Dan Lintas Budaya, 2(2), 107-126. https://doi.org/10.15575/rjsalb.v2i2.3099

Adibah, I. Z. (2017). Pendekatan Sosiologis Dalam Studi Islam. Inspirasi: Jurnal Kajian Dan Penelitian Pendidikan Islam, 1(1), 1-20.

Adriyanto, Y. et. all. (2009). Database Majelis Taklim Propinsi Jawa Tengah. Semarang.

Aisyah, S. (2018). Strategi Majelis Taklim Terhadap Pengembangan Dakwah. Jurnal Berita Sosial, 6(6), 12-23.

Al Faruq, U. (2020). Politik dan Kebijakan tentang Majelis Taklim di Indonesia (Analisis Kebijakan Peraturan Menteri Agama No. 29 Tahun 2019). Al Murabbi, 5(2), 41-59. https://doi.org/10.35891/amb.v5i2.2138

Anis, M. (2013). Spiritualitas di Tengah Modernitas Perkotaan. Jurnal Bayan, 2(4), 1-15.

Arisandy, Y., \& Eenfryanti, Y. (2019). The Empowerment of Majelis Taklim in Developing Independence of Household Economy in The Community of Kampung Nelayan Sejahtera of Bengkulu City. Madania, 23(2), 181-190. https://doi.org/10.29300/madania.v23i2.2630 
Barton, G. (1999). Biografi Gus Dur. Yogyakarta: Hutamedia.

Connolly, P. (2002). Approaches to the Study of Religion terj.Imam Khoiri. Yogyakarta: LKiS.

Dahlan, Z. (2019). Peran dan Kedudukan Majelis Taklim di Indonesia. Jurnal Al-Fatih, 2(2), 252-278.

Dhestiana, N. (2018). Islam dan Hak Asasi Manusia dalam Konsepsi Fathi Osman. Al Yasini, 3(1), 84-95. https://doi.org/10.15642/islamica.2011.5.2.309-325

Engineer, A. A. (2004). Islam and Muslims in India. Problems of identity and existence. Oriente Moderno. https://doi.org/10.1163/22138617-08401006

Erliyana, R., \& Huda, S. (2019). Actualization of Pancasila Values (Indonesian Ideology) in Majelis Taklim Organization. Al-Hayat: Journal of Islamic Education, 3(1), 68-81. https://doi.org/10.35723/ajie.v3i1.46

Faishol, A. et. all. (2007). Metode dan Teknik Kuliah Kerja Transformatif; Implementasi Participatory Action Research (PAR) dan Participatory Rural Appraisal (PRA) Untuk Aksi Perubahan Sosial. Surakarta: P3M STAIN Surakarta.

Habib, Z. (2018). ( Pandangan Kyai Abdullah Faishol tentang Ketahanan Budaya dan Visi NU Sukoharjo ). Jurnal SMaRT, 04(02), 161-178. https://doi.org/https://doi.org/10.18784/smart.v4i2.653

Haryanto, J. T. (2012). Interaksi dan Harmoni Umat Beragama. Walisongo: Jurnal Penelitian Sosial Keagamaan, 20(1), 211-234. https://doi.org/10.21580/ws.20.1.197

Hasibuan, A. S. (2020). Peranan Majelis Taklim Nurul Barkah dalam Pendidikan Keluarga Sakinah di Desa Paringgon Kecamatan Ulu Barumun Kabupaten Padang Lawas. IAIN Padang Sidimpuan.

Huda, I. (2019). Pemberdayaan Masyarakat Berbasis Multikultural di Majelis Taklim An Najach Magelang. Inferensi: Jurnal Penelitian Sosial Keagamaan, 13(2), 253-278. https://doi.org/10.18326/infsl3.v13i2.253-278

Jadidah, A. (2016). Paradigma Pendidikan Alternatif: Majelis Taklim Sebagai Wadah Pendidikan Masyarakat. Jurnal Pusaka, 4(1), 27-42.

Jamil, M. M. (2013). Revitalisasi Islam Kultural. Walisongo: Jurnal Penelitian Sosial Keagamaan, 21(2), 271-308. https://doi.org/10.21580/ws.2013.21.2.245

Langham, T. C., \& Kurtz, L. (1996). Gods in the Global Village: The World's Religions in Sociological Perspective. Sociology of Religion, 57(2), 219-221. https://doi.org/10.2307/3711956

Mibtadin. (2018). The Urban Sufism, Social Movement and The 'Smiling' Islam: A case study of "Hubbun Nabi" Kartasura, Sukoharjo. Analisa: Journal of Social Science and Religion, 3(1), 93-112. https://doi.org/10.18784/analisa.v3i1.591

Mibtadin, M. (2020). Transformasi Rural Sufism ke Spiritualitas Kemanusiaan Kalangan Muslimat NU Kedunggalar, Kabupaten Ngawi, Jawa Timur. Jurnal SMART (Studi Masyarakat, Religi, Dan Tradisi), 6(1), 97112. https://doi.org/10.18784/smart.v6i1.830

Na'im, A. A. (1997). Dekonstruksi Syari'ah: Wacana Kebebasan Sipil, Hak Asasi Manusia dan Hubungan dalam Islam. In Hak Asasi Manusia dan Hubungan Internasional dalam Islam. Yogyakarta: LKiS.

Nadziroh, A. (2020). Strategi penguatan budaya religius dalam membentuk karakter. Religious: Jurnal Studi AgamaAgama Dan Lintas Budaya, 4(1), 64-72. https://doi.org/10.15575/rjsalb.v4i1.6432

Nopriyansa, E. (2020). Agama Sebagai Transpormasi Sosial. El-Ghiroh, 18(01), 1-6. https://doi.org/10.37092/elghiroh.v18i01.156

Nugraha, F. (2018a). Gerakan Ekonomi Keagamaan dan Politik Identitas Muslim Pedesaan ( Studi di BMT Dana Akhirat Kecamatan Arjasari Kabupaten Bandung ). Jurnal Bimas Islam, 2(4), 693-722.

Nugraha, F. (2018b). Majelis Taklim sebagai Basis Pemberdayaan Umat. Tatar Pasundan: Jurnal Diklat Keagamaan, 12(33), 105-113. https://doi.org/10.38075/tp.v12i33.60

Pabbajah, M. (2020). Resepsi dan Resistensi: Respons Masyarakat terhadap Jamaah An-Nadzir sebagai Komunitas Muslim di Tengah Arus Demokratisasi di Indonesia. Religious: Jurnal Studi Agama-Agama Dan Lintas Budaya, 4(4), 251-266. https://doi.org/10.15575/rjsalb.v4i4.10039

Putra, A. E. (2013). Tasawuf Sebagai Terapi Atas Problem Spiritual Masyarakat Modern. Al-Adyan, 8(1), 45-57. https://doi.org/10.24042/ajsla.v8i1.525

Riyadi, A. (2019). Pengembangan Masyarakat Lokal Berbasis Majelis Taklim Di Kecamatan Mijen Kota Semarang. Jurnal Ilmu Dakwah, 38(1), 1-30. https://doi.org/10.21580/jid.v38.1.3966

Rosidin. (2014). Sufisme Perkotaan dan Nalar Beragama Inklusif (Studi atas Peran Majelis Jamuro dalam Upaya Deradikalisasi Gerakan Keagamaan di Surakarta). Analisa: Journal of Social Science and Religion, 21(1). https://doi.org/https://doi.org/10.18784/analisa.v21i1.24

Roviana, S. (2014). Gerakan Perempuan Nahdlatul Ulama dalam Transformasi Pendidikan Politik. Jurnal Pendidikan Islam, 3(2), 403. https://doi.org/10.14421/jpi.2014.32.403-424

Rustan, A. S. (2018). Peran Majelis Taklim Anas bin Malik dalam Membina Silaturrahim Masyarakat di Kabupaten Pare-Pare. Jurnal Al-Khitabah, 4(1), 87-101.

Saidi, A. (2004). Makalah pada Workshop Pengembangan Penelitian Non-Positivistik Bagi Dosen-Dosen PTAI Se-Indonesia. Surakarta: P3M STAIN Surakarta-Ditjen Binbaga Islam Depag RI. 
Sarbini, A. (2014). Internalisasi Nilai Keislaman Melalui Majelis Taklim. Jurnal Ilmu Dakwah, 5(16), 53. https://doi.org/10.15575/jid.v5i16.355

Siraj, S. A. (2013). Meneguhkan Islam Nusantara. Biografi Pemikiran dan Kiprah Kebangsaan Prof. Dr. KH. Said Aqil Siraj, MA. Jakarta: Khalista.

Siraj, S. A. (2014). Islam Sumber Inspirasi Budaya Nusantara. Menuju Masyarakat Mutamaddin. Jakarta: LTNU.

Sodik, M. (2006). "Pendekatan Sosologi" dalam Dudung Abdurrahman (ed.) Metodologi Penelitian Agama. Yogyakarta: Kurnia Kalam Semesta.

Strauss, Anselm dan Corbin, J. (2007). Dasar-dasar Penelitian Kualitatif; Tata Langkah dan Teknik-teknik Teoritisasi Data. Yogyakarta: Pustaka Pelajar.

Sugiyono. (2016). Memahami Penelitian Kualitatif. Bandung: Alfabeta.

Syukur, M. A., \& Muhaya, A. (2015). Economic Movements within Sufism in Java: A Case Study on Qadiriyah and Naqsyabandiyah Sufi Orders. Journal of Indonesian Islam, 9(2), 229-256. https://doi.org/10.15642/JIIS.2015.9.2.229-256

Tischler, H. L. (1990). Introduction to Sociology. Chicago: Holt, Rinehart and Winston.

Wahid, A. (1994). Agama dan Demokrasi. Ahmad Suaedi, dkk. (ed.). Spiritualitas Baru: Agama dan Aspirasi Rakyat. Yogyakarta: Institut Dian/Interfidai.

Wahid, A. (1999). Mengurai Hubungan Agama dan Negara. Jakarta: Grasindo.

Wahid, A. (2006). Islamku, Islam Anda, Islam Kita: Agama Masyarakat Negara Demokrasi. Jakarta: The Wahid Institute. Wahid Abdurrahman. (1989). Islam Indonesia Menatap Masa Depan. Jakarta: P3M.

Wahid, M. (2010). Peta Intelektualisme dan Tema Pokok Pemikiran Gus Dur. In I. Nafi'a (Ed.), Gus Dur di Mata Wong Cirebon. Yogyakarta: Pilar Media.

Zularham, R. (2019). Kaum Muda Muslim Milenial dan Radikalisme (Studi atas Peran Pemuda Majelis Taklim The Rabbaanians, Al-Azhar, Jakarta Selatan dalam Mencegah Radikalisme pada Generasi Muda di Jakarta). UIN Syarif Hidayatullah.

(C) 2021 by the authors. Submitted for possible open access publication under the terms and conditions of the Creative Commons Attribution (CC BY SA) license (https://creativecommons.org/licenses/by-sa/3.0/). 
This page is intentionally left blank 